\title{
Epithelioid Hemangioendothelioma: clinicopathologic, immunhistochemical, and molecular genetic analysis of 39 cases
}

Uta Flucke ${ }^{1 *}$, Rob JC Vogels ${ }^{1}$, Nicolas de Saint Aubain Somerhausen ${ }^{2}$, David H Creytens ${ }^{3}$, Robert G Riedl ${ }^{4}$, Joost M van Gorp ${ }^{5}$, Anya N Milne ${ }^{5}$, Clement J Huysentruyt ${ }^{6}$, Marian AJ Verdijk ${ }^{1}$, Monique M van Asseldonk ${ }^{1}$, Albert JH Suurmeijer ${ }^{7}$, Johannes Bras ${ }^{8}$, Gabriele Palmedo ${ }^{9}$, Patricia JTA Groenen ${ }^{1}$ and Thomas Mentzel ${ }^{9}$

\begin{abstract}
Background: Epithelioid hemangioendothelioma is a malignant, often indolent vascular tumor which occurs at various anatomic sites. Based on a reciprocal translocation $\mathrm{t}(1 ; 3)(\mathrm{p} 36 ; \mathrm{q} 25)$, a consistent WWTR1-CAMTA1 fusion gene has been found. An alternate YAP1-TFE3 fusion has been detected in a small and distinct subset of cases.

Methods: Thirty-nine tumors, from 24 females and 15 males with an age range 9-85 years, were located in soft tissue (head and neck [8], trunk [5], upper extremities [3], lower extremities [2], mediastinal [1], and paratesticular [1]), lymph node (1), breast (1), skin (2), bone (6), lung (7), and liver (2). The cases were investigated using a panel of immunohistochemical markers. The aforementioned fusion-genes were examined using RT-PCR and/or FISH in order to validate their diagnostic value.

Results: Follow-up available for 17 patients ranged from 3 months to 7 years (median interval 1.5 years). Eleven patients were alive without disease, 2 patients were alive with disease after 1.5 and 2 years, respectively. Four patients died of disease after 4 months $(n=1), 5$ months $(n=2)$, and 1.5 years $(n=1)$.

The size, known for 30 lesions, was $>3 \mathrm{~cm}$ in 9 of them. Histologically, all lesions had classical features, at least focally. Four tumors counted $>3$ mitoses/50 HPF.

Immunohistochemically, all cases tested stained positive for ERG (21), FLI1 (5) and CD31 (39). CD34 and D2-40 positivity was seen in $81 \%$ and $71 \%$ of the examined cases, respectively. 11/35 cases expressed pan-keratin and 6/20 cases CK8.18. TFE3 showed a nuclear reaction in 21/24 cases, irrespective of TFE3 rearrangement. Molecular genetically, 35/35 cases revealed one of the fusion genes by FISH and/or RT-PCR with WWTR1-CAMTA1 in 33 cases and YAP1-TFE3 in 2 cases.
\end{abstract}

Conclusions: These results demonstrate the high diagnostic value of FISH and RT-PCR in detecting the fusion genes of EHE. The immunohistochemical utility of TFE3 appears questionable in this study.

Virtual Slides: The virtual slide(s) for this article can be found here: http://www.diagnosticpathology.diagnomx. eu/vs/4010279141259481

Keywords: Epithelioid hemangioendothelioma, Vascular tumors, Soft tissue, Bone, Skin, Lung, Liver

\footnotetext{
* Correspondence: uta.flucke@radboudumc.nl

${ }^{1}$ Department of Pathology, Radboud University Medical Center, P.O. Box

9101, 6500 HB Nijmegen, The Netherlands

Full list of author information is available at the end of the article
} 


\section{Background}

Epithelioid hemangioendothelioma (EHE), first described by Weiss and Enzinger in 1982, is a malignant vascular neoplasm with indolent behavior in the majority of cases [1]. Although, a progressive clinical course with tumorrelated fatality has been documented in some instances, this lesion does not behave as aggressively as a conventional angiosarcoma [1-4].

EHEs arise in soft tissue, bone, skin and various parenchymatous organs [1-7].

The rarity of this tumor type, combined with the wide age distribution at presentation, the variety of anatomic sites and, in some cases, early metastases or multifocal disease leads to a wide range of differential diagnoses. This is complicated by the bland epithelioid cytomorphology and the presence of subtle, mostly intracytoplasmic, vascular lumina [1,2]. Classically, the vacuolated endothelial cells are arranged in short cords and strands recapitulating the primitive angiogenic cords of the yolk sac [8].

After discovering the nonrandom reciprocal $t$ $(1 ; 3)(\mathrm{p} 36 ; \mathrm{q} 25)$ translocation [3], the corresponding fusion gene WWTR1-CAMTA1 was detected [5,9]. More recently, an alternative gene fusion, YAP1-TFE3, was found in a small subset of lesions with distinct morphology and arising mainly in young patients [10].

In this study we have used a large cohort of cases from different anatomical sites to investigate the known fusion genes by fluorescent in situ hybridization (FISH, fusion probe) and reverse transcriptase-polymerase chain reaction (RT-PCR) in order to validate their diagnostic value. Furthermore, we have expanded immunohistochemical data with ERG, the most recently described antibody for endothelial differentiation, as well as TFE3, one of the known fusion proteins.

\section{Methods}

The cases were retrieved from the (referral) files of the authors, and clinical details and follow-up were obtained from the referring physicians. Case 8 was already included in the series by Antonescu et al. [10]. The study was performed in accordance with the Code of Conduct of the Federation of Medical Scientific Societies in the Netherlands and Germany.

In all cases, the tissue was fixed in $4 \%$ buffered formalin, routinely processed and embedded in paraffin; $2-4 \mu \mathrm{m}$ thick sections were stained with hematoxylin and eosin and immunohistochemically by the labelled Streptavidin Biotin technique using commercially available antibodies listed in Table 1. Appropriate positive and negative controls were used throughout.

\section{Fluorescent in situ hybridization (FISH)}

Interphase FISH was performed using a WWTR1-CAMTA1 fusion probe (BACs RP11-1120, RP11-980). The red signal
Table 1 Details of used immunohistochemical antibodies

\begin{tabular}{llll}
\hline Antibody & Clone & Dilution & Source \\
\hline ERG & EPR3864 & $1: 2000$ & ABCam, Cambridge, UK \\
CD31 & JC70 A & $1: 100$ & DAKO, Glostrup, Denmark \\
CD34 & My10 & $1: 100$ & BD Biosciences, Heidelberg, Germany \\
Pankeratin & AE1/3 & $1: 50$ & DAKO, Glostrup, Denmark \\
CK8.18 & CAM5.2 & $1: 10$ & Becton Dickinson, San Jose, USA \\
D2-40 & D2-40 & $1: 100$ & DAKO, Glostrup, Denmark \\
EMA & MC5 & $1: 400$ & BioGenex, San Ramon, USA \\
ASMA & 1A4 & $1: 500$ & DAKO, Glostrup, Denmark \\
S-100 & polyclonal & $1: 2000$ & DAKO, Glostrup, Denmark \\
Fli1 & polyclonal & $1: 50$ & Santa Cruz Biotechnology, \\
TFE3 & polyclonal & $1: 2000$ & Santa Cruz Biotechnology, \\
& & & Heidelberg, Germany \\
INI1 & 25/BAF47 & $1: 50$ & BD Biosciences, Heidelberg, Germany \\
\hline
\end{tabular}

(rhodamine) flanked the distal region of WWTR1 while the green signal (FITC) labeled the proximal region of the CAMTA1 gene.

$3 \mu \mathrm{M}$ sections were deparaffinized with xylene and dried with ethanol after baking at $56^{\circ} \mathrm{C}$ for 16 hours. All tissue sections were pre-treated with a $30 \%$ solution of pre-treatment powder in $2 \mathrm{xSSC}$ and digested for $10 \mathrm{mi}-$ nutes with Proteinase $\mathrm{K}$ according to the instructions of the suppliers (MP Biomedicals Illkirch, France). After a second dehydrating step, the probes were applied to the sections and the covered slides were sealed with rubber cement, heat-denatured and hybridized at $37^{\circ} \mathrm{C}$ for 16 hours. Subsequently, all sections were counterstained with DAPI I in mounting medium $(1000 \mathrm{ng} / \mathrm{ml}$, Abbott, Wiesbaden, Germany) and visualized under a Zeiss Axioplan microscope using a HBO103 lamp and the appropriate filters for the three fluorescent dyes. A negative control was used in each case. A case was interpreted as positive when at least 10 of 50 counted tumor cells (20\%) showed a (yellow) fusion signal.

\section{Reverse transcriptase-Polymerase chain reaction (RT-PCR)}

RNA was extracted from formalin-fixed and paraffinembedded tissues (FFPE) using RNA-Bee-RNA isolation reagent (Bio-Connect BV, Huissen, the Netherlands) according to standard procedures. RNA quantity and quality were determined by NanoDrop measurement (Fisher Scientific, Landsmeer, the Netherlands) and, subsequently, cDNA synthesis was performed using Superscript II (Invitrogen Life Technologies Europe, Bleiswijk, the Netherlands) and random hexamers (Promega Nederland, Leiden, the Netherlands).

The cDNA was tested by the reverse transcriptionpolymerase chain reaction (RT-PCR) for the $H M B S$ (hydroxymethylbilase synthase) housekeeping gene using 
the primers forw150 5'-TGCCAGAGAAGAGTGTGGT G-3', rev150 5'-ATGATGGCACTGAACTCCTG-3', forw250 5'- CTGGTAACGGCAATGCGGCT-3', rev250 5'- TTCT TCTCCAGGGCATGTTC-3'.

For detection of the $\mathrm{t}(1 ; 3)$ (p26.3;q25) translocation, the following primers were used: WWTR1 (NM_001168278.1) forward primers in exon3 5'-GCTGGGAGATGACCTT CACGGC-3' and exon4 5'-CCGTCAGTTCCACACCA GTGCCTC-3' and CAMTA1 (NM_015215.2) reverse primers in exon8 rev 5'-GGCTGGGGCTTGGTCTGGT G-3' and, because of the use of FFPE tissues with suboptimal RNA/cDNA quality, multiple exon9 primers were used: (1) exon9 rev 5'-GCGAGATGATGCGGTGTTTG GC-3', (2) exon 9 rev 5' CTCGGTGCTGCTCTGGTGCA G-3', (3) exon 9 rev 5'- CACCGGGCTGTCCACCATG TC-3' and (4) exon 9 rev 5'-GGACAGGCTCTCCGAGC TGCC-3'.

For the detection of the YAP1-TFE3 fusion, the primers YAP1 (NM_001130145.2) exon1 forw 5'- CTCCGGAAG CTGCCCGACTCC-3' and TFE3 (NM_006521.4) exon4 rev 5'-GAGTGTGGTGGACAGGTACTG-3, TFE3 exon 6 rev 5'- GTTGCTGACAGTGATGGCTGG-3', TFR3 exon 8 rev 5'-CGGGTCACTGGACTTAGGGATGAGA-3' and TFE3 exon 10 rev 5'- CCTGCCCTCCTCCTCAATGT CC-3' were used. The PCR products were analyzed by agarose gel electrophoresis. The sequence of the differently sized PCR-products was obtained by Sanger sequencing and confirmed the presence of the fusion gene.

Negative controls for RT-PCR were 2 epithelioid hemangiomas, 1 epithelioid fibrous histiocytoma, 1 angiosarcoma, 1 epithelioid sarcoma-like/pseudomyogenic hemangioendothelioma and 1 soft tissue angiofibroma.

\section{Results}

Clinical data

Clinical data are presented in Table 2.

Of the 39 patients, 24 were females and 15 were males. The age ranged from 9 to 85 years (mean 50 years; median 51 years). Anatomical sites of soft tissue lesions were as follows: head and neck region (8), trunk (5), upper extremities (3), lower extremities (2), mediastinal (1) and paratesticular (1). One tumor was located in an inguinal lymph node, one in the breast, and 2 lesions in the skin (finger, pubic region). Six neoplasms arose in the bone and 7 in the lung with multifocal disease in 4 cases. Two tumors were situated in the liver. One of them showed multifocality. Metastatic disease was diagnosed in 11/19 cases with occurrence in lymph nodes (Cases 2, 24, 28, 35), lung (Cases 19 and 29), pleura (Cases 19, 23, 34, 36), bone (Cases 29 and 34), chest wall (Case 37), mediastinum (Case 19), mesentery (Case 34), and vulva (Case 32 ). Three patients had metastases to multiple sites (Cases 19, 29, 34).
All but 3 tumors were treated by surgery with wide excision in 15 cases and marginal excision in 9 cases. Additional radiotherapy was applied in 5 cases and metastasectomy was performed in Cases 2, 24 (cervical lymph node) and 34 (mesentery). One patient (Case 19) received pazopanib when metastases and progression were obvious. Two patients were treated by chemotherapy only (Cases 23 and 36). Another patient with multifocal lung disease received radio-chemotherapy (Case 37 ).

Follow-up information, available for 17 patients, ranged from 3 months to 7 years (median interval 1.5 years). Eleven patients were alive without disease, 2 patients were alive with disease after 1.5 and 2 years, respectively. Four patients died of disease after 4 months $(\mathrm{n}=1), 5$ months $(\mathrm{n}=2)$, and 1.5 years $(\mathrm{n}=1)$. Two of them were children.

The patient from Case 8 had a diagnosis of Langerhans cell histiocytosis 11 years prior to the EHE. Case 19 was known with a previously excised cutaneous leiomyosarcoma.

\section{Gross findings}

Tumor size ranged from 0.5 to $11 \mathrm{~cm}$ (mean $3 \mathrm{~cm}$ ). The cut surface appeared solid, white-tan and showed some hemorrhage in a number of cases.

\section{Histological findings}

All tumors showed an infiltrative growth with relatively sharp demarcation in 13 cases. Multinodularity was observed in 10 cases with separate nodules in some of these cases. Vasculocentric growth was present in 15 tumors with occasional intravascular expansion and occlusion of larger vessels. Dabska-like intravascular projections were seen in one case (Case 30). Perineural invasion was found in 5 tumors (Cases 2, 3, 10, 11, 13).

All lesions were composed of epithelioid cells arranged in strands, cords and nests. There was also often a histiocytoid cellular appearance. Additional fusiform cells were seen in 20 cases. Solid highly cellular areas were encountered in 10 cases (Cases 6, 9, 15, 17, 21, 30, 34, $35,37,39)$ (Figure 1). The nuclei were commonly vesicular with small often distinct nucleoli. Mild nuclear atypia was at least focally observed in 16 lesions and striking nuclear atypia in another 12 cases (Cases 6, 8, 11, 12, 14, 15, 17, 24, 25, 32, 38, 39) (Figures 2 and 3). Mitoses ranged from 0 to 22/50 HPF. The 2 tumors with the highest mitotic index showed respectively 12 and $22 \mathrm{mi}-$ totic figures/50 HPF (Cases 30 and 34). Two lesions showed 4 mitotic figures/50 HPF (Cases 32 and 37) and all other lesions did not exceed 3 mitoses/50 HPF. Nuclear pseudoinclusions were seen in the cases with increased atypia. All lesions showed an abundant hyaline cytoplasm with variable intracytoplasmic vacuoles. More or less well-formed multicellular vascular channels were present in 11 lesions and this was a prominent feature in 
Table 2 Clinical data

\begin{tabular}{|c|c|c|c|c|c|c|}
\hline Case & Sex/Age & Site & Size $(\mathrm{cm})$ & Therapy & Rec/Met, $\mathrm{m}$ & Follow-up \\
\hline 1 & $f / 42 y$ & toe & 2.0 & $E$ & NA & NA \\
\hline 2 & $f / 63 y$ & occipital & 1.0 & WE, RT, ME & cerv LN, 14 & NED, $2 y$ \\
\hline 3 & $f / 58 y$ & groin & NA & NA & NA & NA \\
\hline 4 & $f / 66 y$ & lung (mf) & NA & NA & NA & NA \\
\hline 5 & $\mathrm{~m} / 69 \mathrm{y}$ & oral cavity & 0.8 & WE & - & NED, $2 y$ \\
\hline 6 & $\mathrm{~m} / 42 \mathrm{y}$ & groin & 3.6 & NA & NA & NA \\
\hline 7 & $\mathrm{~m} / 10 \mathrm{y}$ & nose bridge & 1.1 & NA & NA & NA \\
\hline 8 & $\mathrm{~m} / 14 \mathrm{y}$ & $L N$, groin & 2.0 & WE & NA & NA \\
\hline 9 & $f / 70 y$ & heel & 1.1 & NA & NA & NA \\
\hline 10 & $\mathrm{~m} / 61 \mathrm{y}$ & skin/finger & 0.5 & WE & - & NED, $2 y$ \\
\hline 11 & $f / 71 y$ & neck & 1.1 & $\mathrm{E}, \mathrm{R} 1$ & - & NED, 7y \\
\hline 12 & $\mathrm{~m} / 51 \mathrm{y}$ & thoracic spine & NA & NA & NA & NA \\
\hline 13 & $f / 30 y$ & upper arm & 1.9 & NA & NA & NA \\
\hline 14 & $\mathrm{~m} / 70 \mathrm{y}$ & lower arm & 2.0 & NA & NA & NA \\
\hline 15 & $f / 85 y$ & paravertebral & 5.4 & NA & NA & NA \\
\hline 16 & $f / 78 y$ & breast & NA & NA & NA & NA \\
\hline 17 & $f / 41 y$ & neck & 2.5 & WE, RT & - & NED, $3 \mathrm{~m}$ \\
\hline 18 & $f / 60 y$ & axilla & 4.5 & E, RT & - & NED, 1y \\
\hline 19 & $\mathrm{~m} / 68 \mathrm{y}$ & lung & 1.4 & $W E, T K l^{*}$ & lung, pleura, mediastinum, 13 & $A W D, 2 y$ \\
\hline 20 & $\mathrm{~m} / 54 \mathrm{y}$ & lung & 2.2 & WE & NA & NA \\
\hline 21 & $\mathrm{~m} / 43 \mathrm{y}$ & mediastinum & 7.5 & $\mathrm{E}$ & NA & NA \\
\hline 22 & $f / 46 y$ & liver (mf) & 4.5 & WE & - & NED, $1 y$ \\
\hline 23 & $f / 70 y$ & liver & NA & $C T$ & pleura, 0 & AWD, $1.5 y$ \\
\hline 24 & $\mathrm{~m} / 49 \mathrm{y}$ & maxilla & 3.1 & WE, RT,ME & cerv LN, 5 & NED, $1 y$ \\
\hline 25 & $f / 26 y$ & humerus & NA & $\mathrm{E}$ & - & NED, $5 y$ \\
\hline 26 & $\mathrm{~m} / 10 \mathrm{y}$ & paratesticular & 1.4 & $\mathrm{E}$ & NA & NA \\
\hline 27 & $f / 55 y$ & rib & 4.5 & WE & NA & NA \\
\hline 28 & $f / 49 y$ & mandible & 2.5 & WE & cerv LN & NA \\
\hline 29 & $f / 37 y$ & neck & 3.0 & $\mathrm{E}$ & LN,bone,lung & $\mathrm{DOD}, 4 \mathrm{~m}$ \\
\hline 30 & f/81y & femur & NA & NA & NA & NA \\
\hline 31 & $\mathrm{~m} / 19 \mathrm{y}$ & lung (mf) & NA & NA & NA & NA \\
\hline 32 & $f / 41 y$ & groin & 1.8 & WE, RT & Vulva & NED, 1y \\
\hline 33 & f/77y & pubic skin & 2.5 & WE & - & NED, 3y \\
\hline 34 & $\mathrm{~m} / 59 \mathrm{y}$ & lung & 3.0 & WE, ME & pleura, bone, mesentery, 3 & DOD, $1.5 y$ \\
\hline 35 & $f / 25 y$ & neck & 7.5 & $E$ & cerv LN, 0 & NA \\
\hline 36 & $f / 9 y$ & lung (mf) & NA & $C T$ & pleura & DOD, $0.5 y$ \\
\hline 37 & $f / 10 y$ & lung (mf) & 11 & $C T, R T$ & chest wall & DOD, $0.5 y$ \\
\hline 38 & $\mathrm{~m} / 51 \mathrm{y}$ & elbow & 2.4 & $E$ & NA & NA \\
\hline 39 & $f / 75 y$ & neck & 2.5 & WE & NA & NA \\
\hline
\end{tabular}

Rec, Recurrence; Met, Metastases; $m$, Months; $y$, Year(s); $E$, Excision; WE, Wide excision; $m f$, Multifocal; NED, No evidence of disease; $A W D$, Alive with disease; $D O D$, death of disease; $R T$, Radiotherapy; $C T$, Chemotherapy; $M E$, Metastasectomy; NA, Not available; cerv, Cervical; $L N$, Lymph node; int jug vein, internal jugular vein; $T K I^{*}$, Tyrosine kinase inhibitor pazopanib.

Case 8 (Figure 3). Some lumina were occluded by hyaline thrombi. A myxohyaline stroma was at least focally present in all cases and some lesions also induced a desmoplastic reaction. Stroma was absent in highly cellular areas. Fifteen neoplasms had (ischemic) necrosis, and calcification was seen in 2 lesions (Cases 9 and 10). 


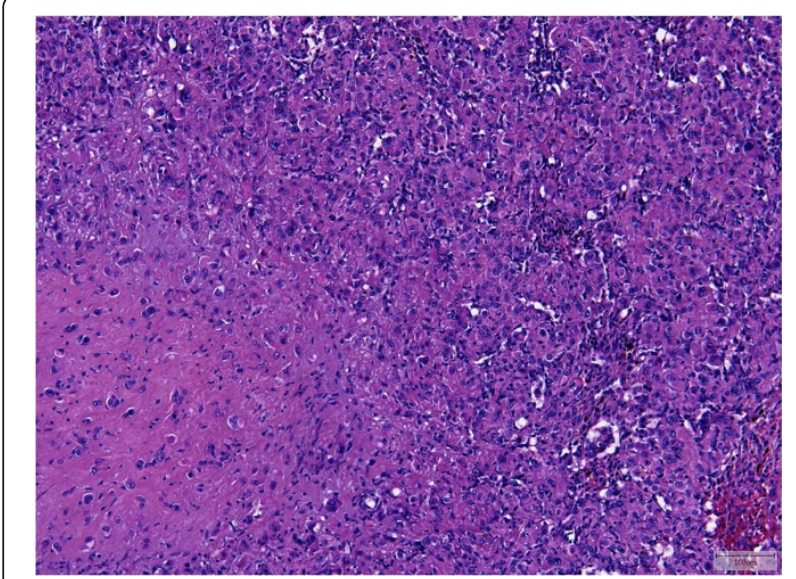

Figure 1 Case 6 showed solid areas without a myxohyaline stroma in addition to the classical morphological features (lower left).

One tumor contained metaplastic bone (Case 15). Multinucleated giant cells were scattered throughout the lesion in one case (Case 39). Hemosiderin deposition and a predominantly marginal inflammatory reaction were seen in some cases.

According to the criteria by Deyrup et al. [4], 12 tumors were classified as high risk with a tumor size $>3 \mathrm{~cm}$ in 9 lesions and a high mitotic rate ( $>3 / 50 \mathrm{HPF})$ in 4 instances including one tumor which showed both. Of the 6 cases with follow-up, 2 patients died of disease (Cases 34 and 37; lung lesions) and 4 were alive without evidence of disease (Cases 18, 22, 24, 32), 2 of them after metastasectomy (lymph node, vulva). In 8 of the 19 cases fulfilling low risk criteria, follow-up was available. Six patients (Cases 2, 5, $10,11,17,33$ ) showed no evidence of disease (one after metastasectomy), while one was alive with metastatic disease (Case 19) and one died of disease (Case 29).

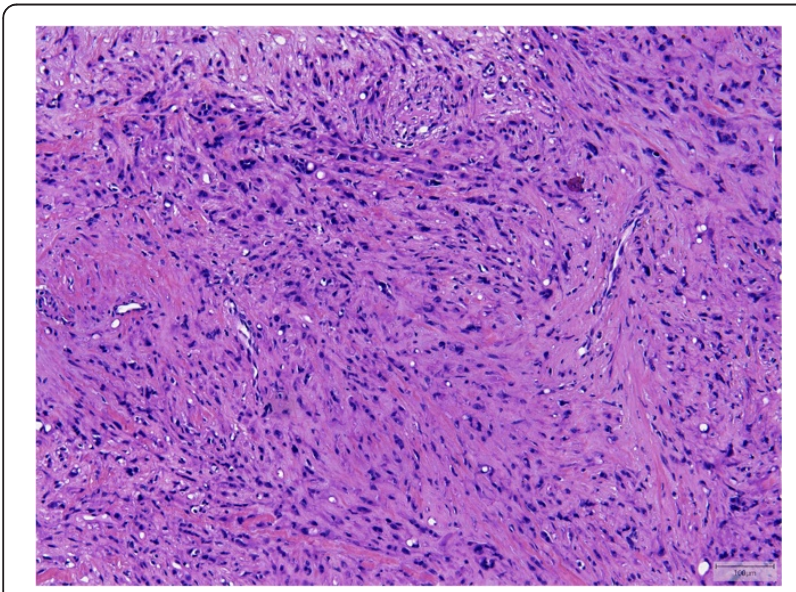

Figure 2 Striking nuclear atypia was seen in approximately $30 \%$ of the cases (Case 14).

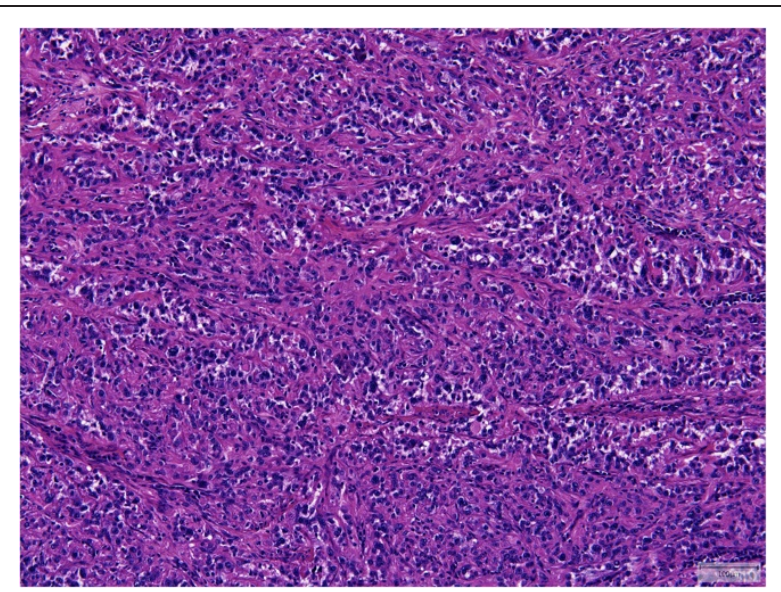

Figure 3 More vasoformative structures and nuclear atypia was present in Case 8 which harbored a YAP1-TFE3 fusion.

\section{Immunohistochemical findings}

The results are shown in Table 3.

21/21 cases were positive for ERG (Figure 4). A membranous reaction for CD31 was demonstrated in all 39 cases (Figure 5) with a focal expression in one case. CD34 staining was seen in 25/31 (81\%) cases with incomplete reaction in 6 samples. FLI1, performed in 5 cases, showed a positive result in all 5 cases. D2-40 was positive in $5 / 7$ cases (71\%). Two of these cases had a focal staining pattern. 11/35 lesions (31\%) stained positive for pan-keratin with a focal reaction in 8 tumors. CK8.18 was focally immunoreactive in $5 / 20$ cases and strongly reactive in another case (30\%). EMA was negative in 10/11 cases. The positive case showed patchy staining (9\%). ASMA was focally expressed in 1/10 lesions (10\%). S-100, which was performed in 11 cases, was patchy positive in 2 of them (18\%). INI1 was retained in all 3 samples tested. TFE3, examined in 24 cases, showed a nuclear reaction, at least focally, in 21 cases (88\%) (Figure 6), including the two TFE3-rearranged neoplasms (Cases 8 and 31).

\section{Molecular genetic findings}

Molecular genetic results are presented in Tables 4 and 5.

The analysis failed for both methods in 4 out of 39 cases (Cases 1, 3, 29, 38). The remaining 35 cases revealed one of the known fusion genes with WWTR1CAMTA1 positivity in 33 cases (94\%) and YAP1-TFE3 in 2 instances (6\%).

In the FISH analysis (fusion probe), 23 out of 38 cases tested, were positive for WWTR1-CAMTA1 (Figure 7) and 3 were negative (including one with a YAP1-TFE3 fusion). 12 samples showed no hybridization result probably due to the poor DNA quality.

Using RT-PCR, 25/28 cases were detected to harbor a fusion gene; 23 were WWTR1-CAMTA1 positive and 2 
Table 3 Immunohistochemical analyses

\begin{tabular}{|c|c|c|c|c|c|c|c|c|}
\hline Case & ERG & CD31 & CD34 & panCK & CK8.18 & EMA & TFE & Others \\
\hline 1 & + & + & $f+$ & + & - & ND & $N D$ & $\mathrm{D} 2-40 \mathrm{f}+$ \\
\hline 2 & $N D$ & + & $f_{+}$ & - & ND & - & + & S100 -, SMA - \\
\hline 3 & ND & + & - & - & ND & - & $f_{+}$ & S100 - \\
\hline 4 & $N D$ & + & - & - & ND & - & - & S100 -, SMA - \\
\hline 5 & ND & + & ND & - & ND & ND & + & $\mathrm{S} 100-$ \\
\hline 6 & ND & + & + & - & ND & ND & $f_{+}$ & SMA -, INI1 + \\
\hline 7 & ND & + & + & - & ND & ND & + & $\mathrm{S} 100 \mathrm{f}+$ \\
\hline 8 & + & + & ND & ND & ND & ND & + & SMA - \\
\hline 9 & ND & + & ND & ND & ND & ND & $\mathrm{f}_{+}$ & SMA - \\
\hline 10 & $\mathrm{ND}$ & + & $f_{+}$ & - & ND & - & $\mathrm{f}_{+}$ & $\mathrm{S} 100 \mathrm{f}+, \mathrm{INI} 1+$ \\
\hline 11 & $N D$ & + & + & - & ND & ND & $f_{+}$ & Fli1 +, D2-40 - \\
\hline 12 & ND & + & + & - & ND & ND & - & Fli1 + \\
\hline 13 & $N D$ & + & ND & $f_{+}$ & ND & ND & + & \\
\hline 14 & ND & + & + & ND & ND & ND & - & Fli1 + \\
\hline 15 & ND & + & ND & ND & ND & ND & $f_{+}$ & Fli1 + \\
\hline 16 & $N D$ & + & ND & - & ND & ND & + & D2-40 + \\
\hline 17 & + & + & + & $f_{+}$ & - & - & $\mathrm{f}_{+}$ & S100 -, SMA - \\
\hline 18 & + & + & + & - & - & ND & + & \\
\hline 19 & + & + & + & $f+$ & $f_{+}$ & - & $\mathrm{f}_{+}$ & D2-40 + \\
\hline 20 & + & + & + & - & - & ND & $\mathrm{f}_{+}$ & \\
\hline 21 & + & + & ND & - & ND & ND & ND & S100 - \\
\hline 22 & + & + & + & - & $f_{+}$ & ND & $\mathrm{f}_{+}$ & \\
\hline 23 & $N D$ & + & + & + & + & $f_{+}$ & ND & D2-40+ \\
\hline 24 & ND & + & - & $f_{+}$ & $f_{+}$ & - & $\mathrm{f}_{+}$ & SMA f+ \\
\hline 25 & ND & + & + & - & - & ND & ND & $\mathrm{S} 100-$ \\
\hline 26 & + & + & $f_{+}$ & - & - & ND & $N D$ & D2-40 -, SMA - \\
\hline 27 & + & + & $f_{+}$ & - & - & ND & $N D$ & \\
\hline 28 & + & + & $f_{+}$ & - & - & ND & ND & \\
\hline 29 & + & + & - & - & - & - & ND & S100 - \\
\hline 30 & + & + & - & - & - & - & $N D$ & SMA - \\
\hline 31 & + & + & + & - & ND & ND & $\mathrm{f}_{+}$ & \\
\hline 32 & + & + & + & $f_{+}$ & $f_{+}$ & ND & ND & $\mathrm{S} 100-$ \\
\hline 33 & + & + & + & - & - & ND & ND & \\
\hline 34 & + & + & + & $f_{+}$ & $f_{+}$ & ND & ND & \\
\hline 35 & $N D$ & + & - & $f_{+}$ & ND & - & $N D$ & Fli1+, INI1 +, \\
\hline 36 & + & + & + & - & - & ND & $N D$ & \\
\hline 37 & + & + & + & $f+$ & - & ND & $\mathrm{f}_{+}$ & \\
\hline 38 & + & + & ND & - & ND & ND & $N D$ & SMA - \\
\hline 39 & + & $f_{+}$ & + & + & - & ND & + & D2-40 f+ \\
\hline$\%+$ & 100 & 100 & 81 & 31 & 30 & 9 & 88 & \\
\hline
\end{tabular}

$\mathrm{ND}$, not done; $\mathrm{f}$, focal expression.

for YAP1-TFE3. Eleven cases were not evaluable because of the poor RNA quality. Seven of these cases were positive for WWTR1-CAMTA1 with FISH. In other words, 8 cases with a detected fusion gene via RT-PCR showed no signal with FISH. Additionally, 3 cases which were negative with RT-PCR had a positive FISH result (WWTR1-CAMTA1). 


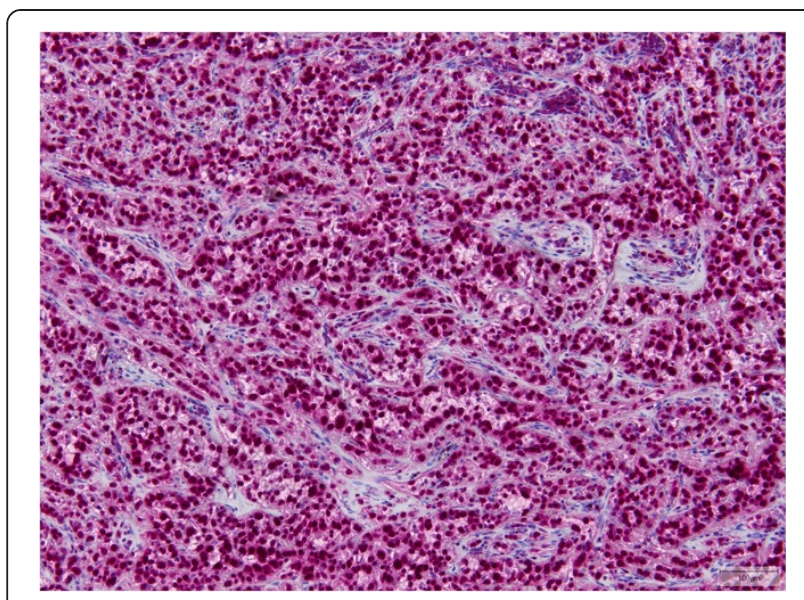

Figure 4 ERG was positive in all cases tested.

Several fusion-transcript variants for WWTR1-CAMTA1 were found: exon 4-exon 8 in 13 cases (Figure 8), exon 4-exon 9 in 7 cases and exon 3-exon 9 in 3 cases.

The fusion-transcript for YAP1-TFE3 were exon 1-exon 4 in both cases (Figure 9).

\section{Discussion}

Similar to other translocation associated tumors, the $\mathrm{t}$ $(1 ; 3)(\mathrm{p} 36 ; \mathrm{q} 23-25)$ or $\mathrm{t}(11 ; \mathrm{X})(\mathrm{q} 13 ; \mathrm{p} 11)$ translocations are seemingly early causative events in EHE oncogenesis $[5,11]$ which initiate a novel transcription program in cells with endothelial properties [5].

The corresponding fusion proteins, WWTR1-CAMTA1 and YAP1-TFE3, may serve as chimeric transcription factors, which manifest their oncogenic function via a promoter switch [5,12]. Another possible oncogenic effect could be due to the loss of regulatory domains of the C-terminus of WWTR1 or YAP1 and the N-terminus of CAMTA1 or TFE3 [5].

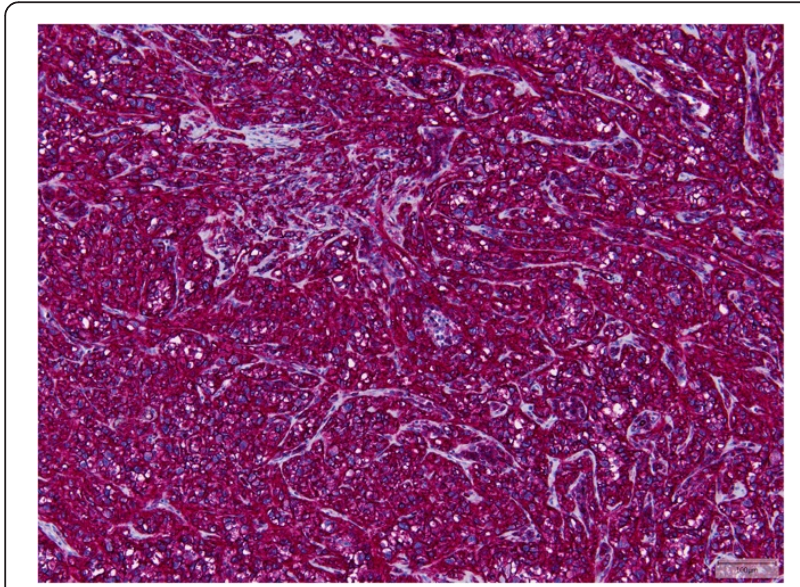

Figure 5 CD31 was strongly expressed in 38/39 cases.

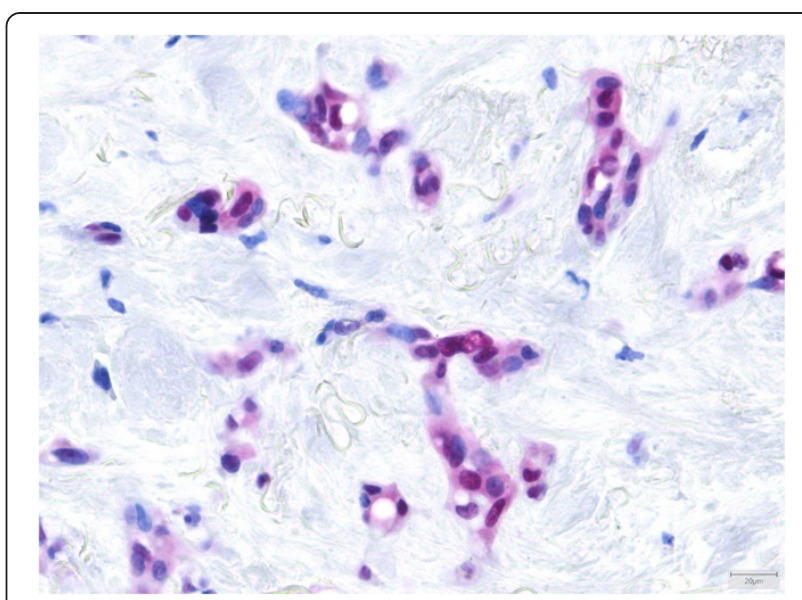

Figure 6 TFE3 showed a nuclear reaction in cases with a WWTR1-CAMTA1 fusion.

WWTR1 on 3q23-24, encodes a transcriptional coactivator involved in mesenchymal stem cell differentiation and is highly expressed in endothelial cells $[5,12]$, while CAMTA1, a calmodulin-binding transcription activator, located on $1 \mathrm{p} 36.23$, has been proposed as an oncogene under the control of the WWTR1 promotor. The latter is supported by the occurrence of an inframe fusion of the $\mathrm{C}$ terminus of CAMTA1 to WWTR1, arguing against loss of function [5].

Alternatively, the YAP1-TFE3 in-frame fusion was recently found in a small and distinct subset of EHE [10].

$Y A P 1$, located on $11 \mathrm{q} 13$, is a member of the FAT-family genes similar to WWTR1, and encodes for another WWdomain containing transcriptional co-activator [10]. The protein of TFE3, located on Xp11.22, is a member of the microphtalmia transcription factor family with oncogenic properties in several tumor types $[10,13]$.

Although these gene fusions have not been identified in other neoplasms, in particular other epithelioid vascular tumors, it is not clear yet whether they are unique to this entity $[5,9]$.

Using both, FISH and RT-PCR, we detected a WWTR1CAMTA1 fusion in 23 cases with discrepancies in 5 cases whereby the results were positive with one method only (and negative for the other). This could be due to the primers used missing potentially new breakpoints (RTPCR) and possibly a low number of tumor cells showing a fusion signal by FISH.

The known WWTR1 breakpoints are in intron 3 and 4 , and the CAMTA1 breakpoints are located in intron 7 and 8 , and at different sites within exon 9 [5,9]. The resulting fusion-transcript variants which we found in our study were exon 4-exon $8(\mathrm{n}=13)$, exon 4-exon 9 $(\mathrm{n}=7)$ and exon 3-exon $9(\mathrm{n}=3)$ (listed in decreasing frequency). 
Table 4 Molecular analyses

\begin{tabular}{|c|c|c|c|}
\hline Case & $\begin{array}{l}\text { WWTR1-CAMTA1 } \\
\text { RT-PCR }\end{array}$ & $\begin{array}{l}\text { WWTR1-CAMTA1 } \\
\text { FISH }\end{array}$ & $\begin{array}{l}\text { YAP1-TFE3 } \\
\text { RT-PCR }\end{array}$ \\
\hline 1 & $x$ & $x$ & $x$ \\
\hline 2 & ex4-ex9 & $x$ & ND \\
\hline 3 & $x$ & $x$ & $x$ \\
\hline 4 & ex4-ex8 & $x$ & ND \\
\hline 5 & ex4-ex8 & Neg & ND \\
\hline 6 & $x$ & Pos & $x$ \\
\hline 7 & Neg & Pos & Neg \\
\hline 8 & Neg & Neg & ex1-ex4 \\
\hline 9 & ex4-ex8 & Pos & ND \\
\hline 10 & ex4-ex8 & Pos & Neg \\
\hline 11 & ex4-ex9 & Pos & ND \\
\hline 12 & ex4-ex9 & $x$ & Neg \\
\hline 13 & ex4-ex8 & Pos & ND \\
\hline 14 & Neg & Pos & Neg \\
\hline 15 & ex4-ex8 & $x$ & ND \\
\hline 16 & ex4-ex8 & $x$ & ND \\
\hline 17 & ex4-ex8 & $x$ & ND \\
\hline 18 & ex4-ex8 & Neg & ND \\
\hline 19 & ex4-ex9 & Pos & Neg \\
\hline 20 & ex4-ex9 & Pos & ND \\
\hline 21 & Neg & Pos & Neg \\
\hline 22 & ex4-ex9 & Pos & Neg \\
\hline 23 & ex4-ex8 & $x$ & ND \\
\hline 24 & ex4-ex8 & Pos & ND \\
\hline 25 & ex3-ex9 & Pos & Neg \\
\hline 26 & X & Pos & $x$ \\
\hline 27 & ex4-ex8 & Pos & ND \\
\hline 28 & $x$ & Pos & $x$ \\
\hline 29 & $x$ & $x$ & $x$ \\
\hline 30 & ex4-ex8 & Pos & ND \\
\hline 31 & Neg & ND & ex1-ex4 \\
\hline 32 & $x$ & Pos & $x$ \\
\hline 33 & $x$ & Pos & $x$ \\
\hline 34 & ex3-ex9 & Pos & Neg \\
\hline 35 & ex4-ex9 & Pos & ND \\
\hline 36 & ex3-ex9 & $x$ & Neg \\
\hline 37 & $x$ & Pos & X \\
\hline 38 & $x$ & $x$ & $x$ \\
\hline \multirow[t]{2}{*}{39} & $x$ & Pos & $x$ \\
\hline & 23 cases Pos & 23 cases Pos & 2 cases Pos \\
\hline
\end{tabular}

Ex, exon; neg, negative; pos, positive; $x$, failed; ND, not done.
Table 5 Fusion-transcripts for both fusion genes

\begin{tabular}{ll}
\hline WWTR1-CAMTA1 & Number of cases \\
\hline exon 4-exon 8 & 13 \\
exon 4-exon 9 & 7 \\
exon 3-exon 9 & 3 \\
\hline YAP1-TFE3 & Number of cases \\
\hline exon 1-exon 4 & 2 \\
\hline
\end{tabular}

Two cases $(6 \%)$ revealed the recently detected fusion YAP1-TFE3 by RT-PCR. One of them (Case 8) was included in the study by Antonescu et al. [10], in which the gene fusion was demonstrated by FISH. This case was not only remarkable because of the histomorphological characteristics as reported in the mentioned paper [10] but also because it occured in a lymph node as the primary site. A more frequently occurring metastasis should be excluded in such cases $[2,14]$. In contrast, the other case with a YAP1-TFE3 fusion showed a classical morphology of a multifocal lung EHE (Case 31). Interestingly, these 2 cases involved adolescents/young adults in concert with the finding of young age reported by Antonescu et al. [10].

TFE3 rearrangements are also present in alveolar soft part sarcoma, certain pediatric renal cancers and a subset of PEComas [15-18]. The use of an antibody against the C-terminal portion of TFE3 seems to be a useful diagnostic tool in all rearranged tumors $[10,19]$, but one has to be aware of an unspecific staining pattern [17] as we found in a proportion of cases with WWTR1-CAMTA1 fusion.

ERG and FLI1 are transcription factors of the ETSfamily which are expressed in endothelial cells. In addition to CD31, these 2 markers are helpful in highlighting the

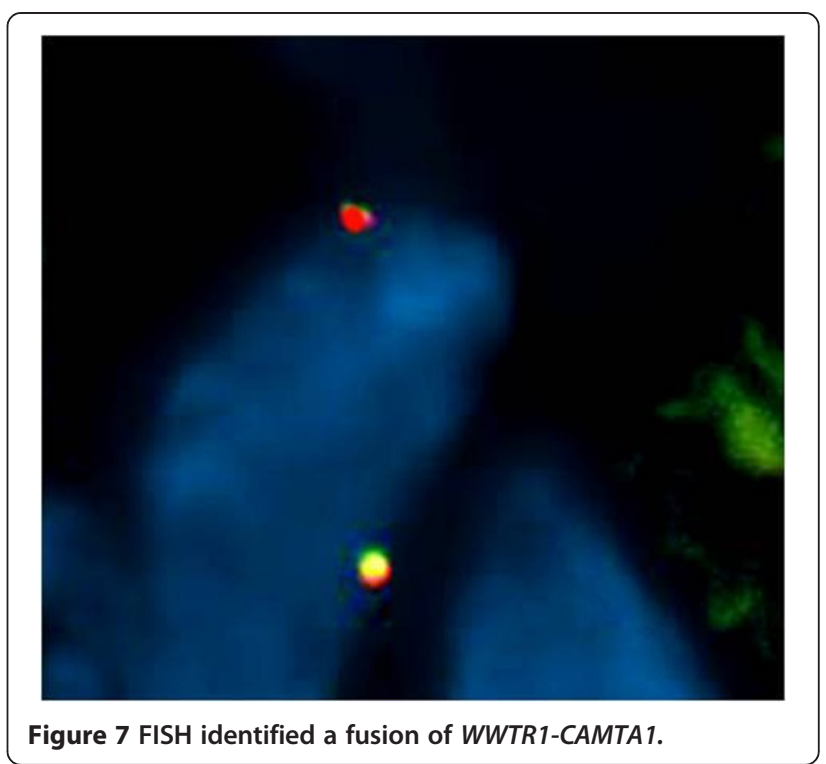




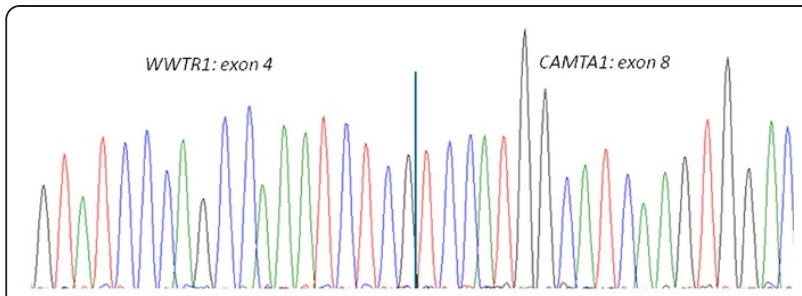

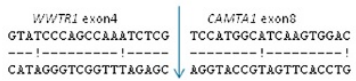

Figure 8 Sequencing of the RT-PCR product shows an in-frame fusion between exon 4 of WWTR 1 and exon 8 of CAMTA 1 in the chimeric transcript in 13 cases.

vascular nature of EHE $[10,20,21]$ and showed expression in all cases examined. These markers are of course expressed in all other vascular lesions $[8,20,21]$, therefore, detection of the aforementioned fusion genes may be a valuable discriminatory tool in diagnosing EHE, especially in difficult cases.

In 2008, a proposal for risk stratification was made based on clinicopathological features of 49 soft tissue EHEs. It seems that higher mitotic activity $(>3 / 50 \mathrm{HPF})$ and tumor size exceeding $3 \mathrm{~cm}$ are associated with higher mortality, irrespective of anatomic site, presence of cytological atypia, tumor cell spindling, or necrosis [4]. Due to the small number of our cases with available clinical data, we were able to show only tendencies for the low-risk and high-risk category. Furthermore, in skin lesions, a favorable outcome is well known similar to all other sarcomas at this site [2]. Whether it is useful to include lung-, liver- and bone lesions in this risk stratification scheme remains uncertain so far, especially with respect to multifocal occurrence (or early metastases) [9].

Differential diagnoses of EHE depend on anatomic site and age. Carcinomas, myoepithelial tumors, epithelioid

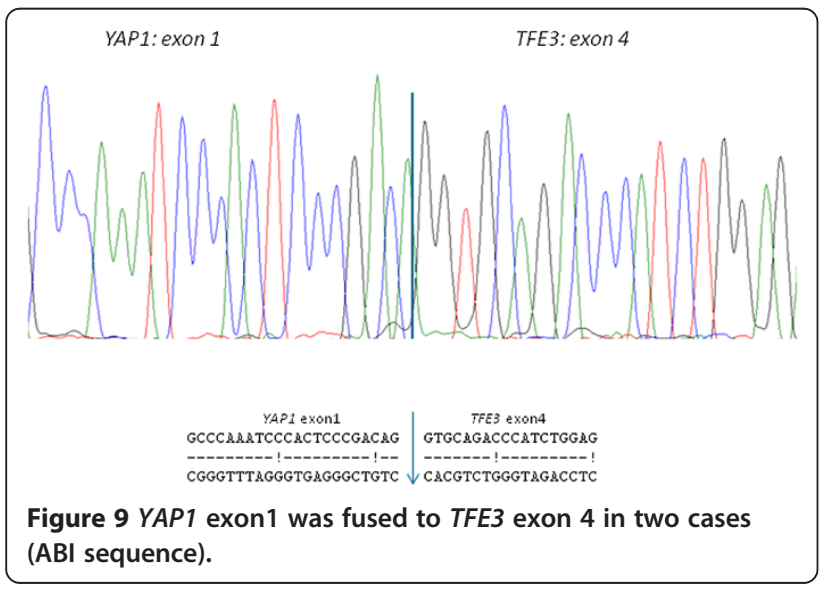

sarcoma, mesothelioma, extraskeletal myxoid chondrosarcoma, myxoid liposarcoma and especially other vascular tumors with epithelioid morphology, such as epithelioid hemangioma, cutaneous epithelioid angiomatous nodule, epithelioid angiosarcoma and pseudomyogenic hemangioendothelioma (epithelioid sarcoma-like hemangioendothelioma, PM-H) can enter the differential diagnoses $[1,2,8,22-24]$. In bone, chondrosarcoma can also be a potential pitfall.

Epithelioid hemangioma occurring in skin, soft tissue and bone is distinguished by a lobular architecture of well-formed vessels with a pericytic cuff, highlighted by ASMA/MSA (muscle specific actin) immunohistochemical reaction $[1,22,25,26]$. In the center of the lesion, the plump epithelioid cells are sometimes rather tightly packed and arranged in solid sheets simulating a more aggressive tumor. The distinctive zonation pattern with peripheral maturation is a helpful finding $[25,26]$. A myxohyaline stroma is not a feature of epithelioid hemangioma. As in EHE, vascular invasion can occur. Multifocality of epithelioid hemangioma with involvement of soft tissue and/or bone, skin and lymph nodes should not be confused with metastases of EHE [26,27].

Cutaneous epithelioid angiomatous nodule is a circumscribed lesion composed of a sheet-like proliferation of epithelioid cells with eosinophilic cytoplasm. Intracytoplasmic vacuoles are numerous and mitotic figures can be present. This lesion lacks cords and strands of tumor cells in a myxohyaline or fibrous stroma which is seen in EHE [22].

Epithelioid cells with eosinophilic cytoplasm are present to a variable extent in approximately $70 \%$ of angiosarcomas (AS) of soft tissue [23] and, of course, they can be prominent in AS at other sites as bone, skin and parenchymatous organs. There is considerable nuclear pleomorphism present and a high mitotic index, which are not typical features of EHE. Lumen formation ranges from irregular vascular channels to intracytoplasmic vacuoles or when absent there can be a diffuse, nest- or sheet-like growth pattern. The hemorrhagic background seen in angiosarcoma is not characteristic for EHE. Keratins can be expressed in both EHE and angiosarcomas (in ca. 30\% of the cases, respectively) [23].

Pseudomyogenic hemangioendothelioma (epithelioid sarcoma-like hemangioendothelioma, PM-H) is composed of loose fascicles and sheets of plump spindle cells and/or epithelioid cells with vesicular nuclei and bright eosinophilic cytoplasm. A myxoid background rarely exists in $\mathrm{PM}-\mathrm{H}$ and (intracytoplasmic) vascular formations are described as more elusive. Angiocentric growth may occur in both entities. Expression of keratins is an overlapping feature, although CD34 and pankeratin MNF116 are lacking in PM-H [8,24]. Recently, SERPINE1-FOSB, has been identified as a specific fusion gene in PM-H [28]. 
Carcinomas tend to manifest as more pleomorphic, mitotically active tumors [1] evoking a desmoplastic response and usually exhibit stronger keratin expression whereas endothelial markers are absent.

Myoepithelial tumors are composed of variable proportions of epithelioid, spindle, clear and/or plasmocytoid cells. However, cords and strands embedded in a (chondro) myxoid/hyaline matrix is a shared feature and cytoplasmic vacuolation can occur [29]. Endothelial markers are absent in myoepithelial tumors. S-100 and keratins, usually expressed in myoepithelial tumors [29], can also be occasionally positive in EHE as demonstrated in two of our cases [2]. EWSR1 and PLAG rearrangements are characteristic genetic changes in myoepithelial tumors [30-33].

Extraskeletal myxoid chondrosarcoma shows a multinodular architecture. The monomorphous small round or short spindle cells are loosely arranged and show delicate anastomosing strands distributed in a prominent myxoid stroma. Although some vacuolated cells can be observed, the cytoplasm is more eosinophilic $[1,34]$ and vascular markers are not expressed. NR4A3 rearrangement is a pathognomonic genetic aberration [35].

Conventional epithelioid sarcoma (ES) tends to grow in confluent nodules with central necrosis or hyalinization. The epithelioid to spindled cells show deeply eosinophilic cytoplasm. Vacuolated cells can possibly be confused with intracytoplasmic lumina of EHE [36]. When the matrix is myxoid, there are often still prominent collagen bundles [37], a feature which is not seen in the myxohyaline stroma of EHE. Immunohistochemically, this tumor type typically shows keratin- and EMA-expression, loss of INI1 [38] and occasionally a membranous CD31 staining [39]. CD34 and D2-40 can be either positive or negative in both tumor types [40-42]. Interestingly, ERG and FLI1 (antibody to the $\mathrm{N}$-terminus) expression was recently shown in up to $70 \%$ and more than $90 \%$ of ES, respectively $[40,41]$. Therefore, these markers can only be interpreted in the right context together with CD31 and INI1. The latter is retained in EHE [38] as shown in some of our cases.

Myxoid liposarcoma shows a prominent myxoid matrix with enhanced cellularity at the periphery of the tumor nodules. The primitive cells are uniformly round to oval-shaped. Small signet ring lipoblasts could possibly be confused with the vacuolated cells of EHE, but there is no abundant paleeosinophilic cytoplasm in a myxoid liposarcoma. The delicate arborizing vasculature in myxoid liposarcoma is very characteristic. When genetics are taken into account, DDIT3 is the consistent fusion partner in this lesion [42].

As well as the aforementioned vascular lesions, chondrosarcoma is an important differential diagnosis in primary bone tumors and shows uniform atypical chondroblasts suspended in an extensive myxoid matrix. Cytoplasmic vacuolation can be misinterpreted but the nuclei in chondrosarcoma are hyperchromatic and the scant cytoplasm is eosinophilic [42]. Vascular immunohistochemical markers are absent.

Epithelioid mesothelioma could be a relevant differential diagnosis at appropriate sites because of the abundant, sometimes vacuolated cytoplasm of mesothelial cells and the possible myxoid stroma. Although pankeratin and D2-40 can be positive in both malignancies, as also demonstrated in a number of our cases, calretinin, keratin $5 / 6$, keratin 7 , and WT1 are typically distinguishing mesotheliomas [43].

\section{Conclusions}

The identification of the fusion genes in EHEs provides important diagnostic information, especially in cases with aberrant morphology or when biopsy material is limited. Moreover, clinicopathologic and research studies can be objectified based on these molecular fusion events, and biological and prognostic information will possibly influence therapeutic approaches.

\section{Abbreviations}

EHE: Epithelioid hemangioendothelioma; PM-H: Pseudomyogenic hemangioendothelioma; ES: Epithelioid sarcoma.

\section{Competing interests}

The authors declare that they no competing interests.

\section{Authors' contributions}

UF, TM, PG designed the study. PG, MV, MA, GP carried out the experiments. UF, TM, PG, AM drafted the manuscript. RV, AS, CH, DC, NS, RR, JB, JG contributed cases and participitated in data analysis. All authors approved the final version of the manuscript.

\section{Acknowledgements}

The authors thank the following pathologists and clinicians who kindly provided case material and clinical follow-up: Dr. Schildhaus (Göttingen), Drs. Bank and Pav (Ravensburg), Drs. Nenning and Hindermann (Leipzig), Dr. Andreev (Bitterfeld), Prof. Dr. Schulz and Dr. Knoblauch (Bad Homburg), Drs. Mairinger and Griff (Berlin), Drs. Teuber, Vogel and Colbow (Leipzig), Prof. Dr. Püschel (Saarbrücken), Prof. Klapper, Dr. Oschlies and Dr. Jänig (Kiel), Dr. Schweigert (Stollberg-Niederdorf), Dr. Brockmann (Cologne), Dr. Oehler (Singen), Prof. Dr. Feiden (Homburg), Prof. Dr. Kuhnen (Münster), Dr. Reisshauer (Neubrandenburg), Dr. Kronsbein (Wangen im Allgäu), Dr. Neumann (Marburg) [Germany], Dr. Seldenrijk (Nieuwegein), Prof. Dr. van Diest, Drs. Vermeulen and van Dalen (Utrecht), Prof. Dr. Merkx, Prof. Dr. van der Graaf en Dr. Schreuder (Nijmegen) [The Netherlands].

We are also grateful to Prof. Dr. C.D.M. Fletcher (Boston, MA, USA), Prof. Dr. C. Fisher (London, UK), and Prof. Dr. P.C.W. Hogendoorn (Leiden, The Netherlands) confirming the diagnosis in one case each.

\section{Author details}

'Department of Pathology, Radboud University Medical Center, P.O. Box

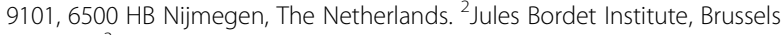
Belgium. ${ }^{3}$ Department of Pathology, Ghent University Hospital, Ghent, Belgium. ${ }^{4}$ Department of Pathology, Maastricht University Medical Center, Maastricht, The Netherlands. ${ }^{5}$ Department of Pathology, Diakonessenhuis Utrecht, Utrecht, The Netherlands. 'Laboratory of Pathological Anatomy and Medical Microbiology (PAMM), Eindhoven, The Netherlands. 'Department of Pathology, University Medical Center Groningen, University of Groningen, Groningen, The Netherlands. ${ }^{8}$ Department of Pathology, Academic Medical Center, Amsterdam, The Netherlands. 'Dermatopathology Bodensee,

Friedrichshafen, Germany. 
Received: 4 April 2014 Accepted: 22 June 2014

Published: 1 July 2014

\section{References}

1. Weiss SW, Enzinger FM: Epithelioid hemangioendothelioma. a vascular tumor often mistaken for a carcinoma. Cancer 1982, 50:970-981.

2. Mentzel T, Beham A, Calonje E, Katenkamp D, Fletcher CD: Epithelioid hemangioendothelioma of skin and soft tissues: clinicopathologic and immunohistochemical study of 30 cases. Am J Surg Pathol 1997, 21:363-374.

3. Mendlick MR, Nelson M, Pickering D, Johansson SL, Seemayer TA, Neff JR, Vergara G, Rosenthal H, Bridge JA: Translocation t $(1 ; 3)(p 36.3 ; q 25)$ is a nonrandom aberration in epithelioid hemangioendothelioma. Am J Surg Pathol 2001, 25:684-687.

4. Deyrup AT, Tighiouart M, Montag AG, Weiss SW: Epithelioid hemangioendothelioma of soft tissue: a proposal for risk stratification based on 49 cases. Am J Surg Pathol 2008, 32:924-927.

5. Tanas MR, Sboner A, Oliveira AM, Erickson-Johnson MR, Hespelt J, Hanwright PJ, Flanagan J, Luo Y, Fenwick K, Natrajan R, Mitsopolous C, Zvelebil M, Hoch BL, Weiss SW, Debiec-Rychter M, Sciot R, West RB, Lazar AJ, Ashworth A, Reis-Filho JS, Lord CJ, Gerstein MB, Rubin MA, Rubin BP: Identification of disease-defining gene fusion in epithelioid hemangioendothelioma. Sci Trans/ Med 2011, 3:98ra82.

6. Jinghong $X$, Lirong C: Pulmonary epithelioid hemangioendothelioma accompanied by bilateral multiple calcified nodules in the lung. Diagn Pathol 2011, 6:21.

7. Li XM, Lin XY, Xu HT, Yu JH, Wang L, Fan CF, Liu Y, Wang EH: Mediastinal epitheloid hemangioendothelioma with abundant spindle cells and osteoclast-like giant cells mimicking malignant fibrous histiocytoma. Diagn Pathol 2013, 8:103.

8. Billings SD, Folpe AL, Weiss SW: Epithelioid sarcoma-like hemangioenothelioma. Am J Surg Pathol 2003, 27:48-57.

9. Errani C, Zhang L, Sung YS, Hajdu M, Singer S, Maki R, Healey JH, Antonescu CR: A novel WWTR1-CAMTA1 gene fusion is a consistent abnormality in epithelioid hemangioendothelioma of different anatomic sites. Genes Chromosomes Cancer 2011, 50:644-653.

10. Antonescu CR, Le Loarer F, Mosquera JM, Sboner A, Zhang L, Chen CL, Chen HW, Pathan N, Krausz T, Dickson BC, Weinreb I, Rubin MA, Hameed M, Fletcher CD: Novel YAP1-TFE3 fusion defines a distinct subset of epithelioid hemangioendothelioma. Genes Chromosomes Cancer 2013, 52:775-784.

11. Mitelman F, Johansson B, Mertens F: The impact of translocations and gene fusions on cancer causation. Nat Rev Cancer 2007, 7:233-245.

12. Cheah AL, Goldblum JR, Billings SD: Molecular diagnostics complementing morphology in superficial mesenchymal tumors. Semin Diagn Pathol 2013, 30:95-109.

13. Haq R, Fisher DE: Biology and clinical relevance of the microophtalmia family of transcription factors in human cancer. J Clin Oncol 2011, 29:3474-3482

14. Chan JK, Frizzera G, Fletcher CD, Rosai J: Primary vascular tumors of lymph nodes other than Kaposi's sarcoma. Am J Surg Pathol 1992, 16:335-350.

15. Ladanyi M, Lui MY, Antonescu CR, Krause-Boehm A, Meindl A, Argani P, Healey JH, Ueda T, Yoshikawa H, Meloni-Ehrig A, Sorensen PH, Mertens F, Mandahl N, van den Berghe H, Sciot R, Dal Cin P, Bridge J: The der (17) t $(X ; 17)(p 11 ; q 25)$ of human alveolar soft part sarcoma fuses the TFE3 transcription factor gene to ASPL, a novel gene at 17q25. Oncogene 2001, 20:48-57.

16. Argani $P$, Antonescu CR, Illei PB, Lui MY, Timmons CF, Newbury R, Reuter VE, Garvin AJ, Perez-Atayde AR, Fletcher JA, Beckwith JB, Bridge JA, Ladanyi M: Primary renal neoplasms with the ASPL-TFE3 gene fusion of alveolar soft part sarcoma: a distinctive tumor entity previously included among renal cell carcinomas of children and adolescents. Am J Pathol 2001, 159:179-192.

17. Argani P, Aulmann S, Illei P, Netto G, Ro J, Cho HY, Dogan S, Ladanyi M, Martignoni G, Goldblum JR, Weiss SW: A distinctive subset of PEComas harbor TFE3 gene fusions. Am J Surg Pathol 2010, 34:1395-1406.

18. Malinowska I, Kwiatkowski DJ, Weiss SW, Martignoni G, Netto G, Argani P. Perivascular epithelioid cell tumors (PEComas) harboring TFE3 gene rearrangements lack the TSC2 alterations characteristic of conventional PEComas: further evidence for a biologic distinction. Am J Surg Pathol 2012, 36:783-784.

19. Argani P, Lal P, Hutchinson B, Lui MY, Reuter VE, Ladanyi M: Aberrant nuclear immunoreactivity for TFE3 in neoplasms with TFE3 gene fusions: a sensitive and specific immunohistochemical assay. Am J Surg Pathol 2003, 27:750-761.

20. Folpe AL, Chand EM, Goldblum JR, Weiss SW: Expression of Fli-1, a nuclear transcriptionfactor, distinguishes vascular neoplasms from potential mimics. Am J Surg Pathol 2001, 25:1061-1066.

21. Miettinen M, Wang ZF, Paetau A, Tan SH, Dobi A, Srivastava S, Sesterhenn I: ERG transcription factor as an immunohistochemical marker for vascular endothelial tumors and prostatic carcinoma. Am J Surg Pathol 2011, 35:432-441.

22. Brenn T, Fletcher CD: Cutaneous epithelioid angiomatous nodule: a distinct lesion in the morphologic spectrum of epithelioid vascular tumors. Am J Dermatopathol 2004, 26:14-21.

23. Meis-Kindblom JM, Kindblom LG: Angiosarcoma of soft tissue: a study of 80 cases. Am J Surg Pathol 1998, 22:683-697.

24. Hornick JL, Fletcher CD: Pseudomyogenic hemangioendothelioma: a distinctive, often muticentric tumor with indolent behavior. Am J Surg Pathol 2011, 35:190-201.

25. Fetsch JF, Sesterhenn IA, Miettinen M, Davis CJ: Epithelioid hemangioma of the penis. a clinicopathologic and immunohistochemical analysis of 19 cases, with special reference to exuberant examples often confused with epithelioid hemangioendothelioma and epithelioid angiosarcoma. Am J Surg Pathol 2004, 28:523-533.

26. Errani C, Zhang L, Panicek DM, Healey JH, Antonescu CR: Epithelioid hemangioma of bone and soft tissue. Clin Orthoped Relat Res 2012, 470:1498-1506.

27. Nielsen GP, Srivastava A, Kattapuram S, Deshpande V, O'Connell JX, Mangham CD, Rosenberg AE: Epithelioid hemangioma of bone revisited. a study of 50 cases. Am J Surg Pathol 2009, 33:270-277.

28. Walther C, Tayebwa J, Lilljebjorn H, Magnusson L, Nilsson J, Vult von Steyern F, Ora I, Domanski H, Fioretos T, Nord KH, Fletcher CDM, Mertens F: A novel SERPINE1-FOSB fusion gene results in transcriptional up-regulation of FOSB in pseudomyogenic haemangioendothelioma. J Pathol 2014, 232:534-540.

29. Hornick $\lrcorner$, Fletcher CD: Myoepithelial tumors of soft tissue: a clinicopathologic and immunohistochemical study of 101 cases with evaluation of prognostic parameters. Am J Surg Pathol 2003, 27:1 183-1196.

30. Antonescu CR, Zhang L, Chang NE, Pawel BR, Travis W, Katabi N, Edelman M, Rosenberg AE, Nielsen GP, Dal Cin P, Fletcher CD: EWSR1-POU5F1 fusion in soft tissue myoepithelial tumors. a molecular analysis of sixty-six cases, including soft tissue, bone and visceral lesions showing common involvement of EWSR1 gene rearrangement. Genes Chromosomes Cancer 2010, 49:1114-1124.

31. Bahrami A, Dalton JD, Krane JF, Fletcher CD: A subset of cutaneous and soft tissue mixed tumors are genetically linked to their salivary gland counterpart. Genes Chromosomes Cancer 2012, 51:140-148.

32. Flucke U, Palmedo G, Blankenhorn N, Slootweg PJ, Kutzner H, Mentzel T: EWSR1 gene rearrangement occurs in a subset of cutaneous myoepithelial tumors: a study of 18 cases. Mod Pathol 2011, 24:1444-1450.

33. Antonescu CR, Zhang L, Shao SY, Mosquera JM, Weinreb I, Katabi N, Fletcher CD: Frequent PLAG1 gene rearrangements in skin and soft tissue myoepithelioma with ductal differentiation. Genes Chromosomes Cancer 2013, 52:675-682.

34. Meis-Kindblom JM, Bergh P, Gunterberg B, Kindblom LG: Extraskeletal myxoid chondrsarcoma: a reappraisal of its morphologic spectrum and prognostic factors based on 117 cases. Am J Surg Pathol 1999, 23:636-650.

35. Hisaoka M, Hashimoto $\mathrm{H}$ : Extraskeletal myxoid chondrosarcoma: updated clinicopathological and molecular genetic characteristics. Pathol Int 2005, 55:453-463.

36. Chase DR, Enzinger FM: Epithelioid sarcoma. diagnosis, prognostic indicators, and treatment. Am J Surg Pathol 1985, 9:241-263.

37. Flucke U, Hulsebos TJ, van Krieken JH, Mentzel T: Myxoid epithelioid sarcoma: a diagnostic challenge. a report on six cases. Histopathology 2010, 57:753-759.

38. Hornick JL, Dal Cin P, Fletcher CD: Loss of INI1 expression is characteristic of both conventional and proximal-type epithelioid sarcoma. Am J Surg Pathol 2009, 33:542-550.

39. Den Bakker MA, Flood SJ, Kliffen M: CD31 staining in epithelioid sarcoma. Virch Arch 2003, 443:93-97.

40. Miettinen M, Wang Z, Sarlomo-Rikala M, Abdullaev Z, Pack SD, Fetsch JF: ERG expression in epithelioid sarcoma. Am J Surg Patho/ 2013, 37:1580-1585 
41. Stockman DL, Hornick JL, Deavers MT, Lev DC, Lazar AJ, Wang WL: ERG and FLI1 protein expression in epithelioid sarcoma. Mod Pathol 2014, 27:496-501.

42. Fletcher CDM, Bridge JA, Hogendoorn PCW, Mertens F: WHO classification of tumours of soft tissue and bone. Lyon: IARC; 2013:39-264.

43. Ordóñez NG: Mesothelioma with signet ring cell features: report of 23 cases. Mod Pathol 2013, 26:370-384.

doi:10.1186/1746-1596-9-131

Cite this article as: Flucke et al.: Epithelioid Hemangioendothelioma:

clinicopathologic, immunhistochemical, and molecular genetic

analysis of 39 cases. Diagnostic Pathology 2014 9:131.

\section{Submit your next manuscript to BioMed Central} and take full advantage of:

- Convenient online submission

- Thorough peer review

- No space constraints or color figure charges

- Immediate publication on acceptance

- Inclusion in PubMed, CAS, Scopus and Google Scholar

- Research which is freely available for redistribution 